\title{
LAS LEYES SINGULARES EN LA DOCTRINA DEL TRIBUNAL CONSTITUCIONAL
}

\author{
The unique laws in the doctrine of the Constitutional Court
}

\author{
JOSÉ ANTONIO MONTILLA MARTOS
}

I. INTRODUCCIÓN.-II. LAS LEYES SINGULARES EN LA DOCTRINA DEL TRIBUNAL CONSTITUCIONAL: DE LA EXCEPCIONALIDAD A LA IMPOSIBILIDAD: 1. La configuración inicial en la STC 166/1986: el límite de la igualdad. 2. El reconocimiento de la tutela judicial efectiva como límite infranqueable para las leyes singulares.-III. LAS LEYES SINGULARES EN EL MARCO DE LA NUEVA DOCTRINA DEL TRIBUNAL CONSTITUCIONAL: 1. La tutela de las leyes singular a instancia del afectado: el amparo frente a leyes. 2. El reforzamiento de las garantías democráticas en el proceso de elaboración.-BIBLIOGRAFÍA CITADA.

\section{INTRODUCCIÓN}

Las SSTC 129/2013 y 203/2013 han reabierto el debate sobre el fenómeno de las leyes singulares en unos términos que resultan relevantes para la propia configuración del concepto constitucional de ley. El Tribunal Constitucional denuncia, y sanciona por ello, que una forma de legislar congruente con las características y necesidades de un Estado social y democrático de Derecho puede ser utilizada por el legislador para impedir el control jurisdiccional que garantiza los derechos e intereses legítimos de los directamente afectados por la ley, especialmente en el caso de leyes autoaplicativas, esto es, leyes que no necesitan un acto administrativo de aplicación en cuanto lo contienen en sí mismas.

El supuesto de hecho al que se refiere la STC 129/2013 es el de la Ley 9/2002, de Castilla y León, sobre declaración de proyectos regionales de infraestructuras de residuos de singular interés. La ley diferencia los proyectos regionales de infraestructuras de residuos de los restantes proyectos regionales regulados en la Ley 10/1998, de ordenación del territorio de la Comunidad 
Autónoma. Sin embargo, es una ley general y abstracta en cuanto sus destinatarios son indeterminados y resulta posible aplicarla de forma reiterada mientras esté vigente. El problema deriva de que prevé la aprobación por ley de los proyectos regionales de infraestructuras de residuos y, en concreto, en su Disposición Adicional Primera establece un supuesto de aplicación de la Ley: la declaración como proyecto regional de este tipo de la planta de Santovenia del Pisuerga (Valladolid) con la consecuencia de su puesto en funcionamiento ope legis, convirtiendo esa Disposición Adicional en norma legal autoaplicativa. A juicio del Tribunal, la reserva formal de ley contenida en esta Ley «conlleva la sustracción a la Administración de la función de aplicación de la norma al caso concreto que, de otra manera, le correspondería». Pero lo realmente novedoso de este pronunciamiento jurisprudencial es la constatación, por el propio Tribunal Constitucional, de las consecuencias constitucionales de esta actuación del legislador. Con ella no se realza la importancia política de una determinada actuación de carácter excepcional o se abre el debate público sobre ella con participación de la minoría política sino justamente lo contrario: se elude o reduce el control jurisdiccional, e incluso el político-parlamentario (aunque esto no lo cuestiona el Tribunal), sobre una decisión política controvertida a través de los instrumentos que el ordenamiento brinda al legislador. No resulta baladí recordar que esta planta de tratamientos de residuos fue cerrada en virtud de una sentencia del Tribunal Supremo y pudo reabrirse como consecuencia de la aprobación de esta disposición legislativa singular de carácter autoaplicativo.

Por su parte, la STC 203/2013 enjuicia la constitucionalidad de la Ley de Castilla y León 6/2007, de aprobación del proyecto regional «Ciudad del Medio Ambiente». A juicio del Tribunal no estamos en este supuesto ante una ley autoaplicativa en cuanto es susceptible de ser aplicada mientras continúe vigente y precisa de actos administrativos de aplicación; tampoco es una ley de estructura singular en atención a los destinatarios a los que va dirigida, pero sí, es, nos dice el Tribunal, una ley singular por su objeto, pues «ha sido dictada en atención a un supuesto de hecho concreto, esto es, a una situación singular o excepcional». Por ello, el Tribunal enjuicia esta ley singular partiendo de la doctrina establecida en la STC 166/1986 con las matizaciones incorporadas por la STC 129/2013, esto es, aplica el test de la «razonabilidad, proporcionalidad y adecuación» a partir de su carácter excepcional pero incorporando la nueva concepción material de la tutela judicial efectiva, más allá del principio de igualdad, de la que deriva su inconstitucionalidad.

La doctrina de ambas sentencias, esbozada en los párrafos anteriores, permite un nuevo acercamiento al fenómeno de las leyes singulares. Sabemos que la transformación de un Estado que se limita a tutelar la certeza del Derecho y

Revista Española de Derecho Constitucional 
la libertad formal en un Estado que interviene en las relaciones económicas y sociales ha producido importantes mutaciones en la estructura formal de la ley. El Estado, y por ende el legislador, debe afrontar requerimientos desconocidos que, en su función normativo-reguladora, conlleva la tarea intervencionista, y, por tanto, sectorial, en una sociedad plural en la que coexisten intereses diversos y contradictorios. La capacidad de articulación de los diversos intereses grupales convierte a la ley en instrumento fundamental para dar respuesta a las necesidades concretas de una sociedad pluralista. Por ello, la ley no puede limitarse a establecer el marco normativo de la actividad social sino que constituye un instrumento de acción social del que puede hacer uso el legislador para satisfacer intereses inmediatos de ciudadanos y grupos, sin la mediación de la administración (C. Starck, 1979, 300). Pero esto tiene efectos colaterales. Mediante leyes singulares pueden promulgarse medidas normativas referidas a personas y situaciones concretas. La ley singular es, en este sentido, un fenómeno característico del Estado social y democrático de Derecho (C. Mortati, 1968, V-VI) (1). Desde esa perspectiva, la intervención legislativa singular y concreta podría aportar la legitimidad democrática directa, no sólo por proceder del órgano vinculado a la voluntad popular sino porque pueden recoger en su procedimiento de elaboración las distintas aportaciones de las minorías en una sociedad pluralista.

Sin embargo, el debate actual vuelve a mostrar, como ya se advirtió a propósito del caso Rumasa, que la ley puede no ser en estos supuestos una ga-

(1) El propio Tribunal Constitucional lo había apuntado en una de sus primeras sentencias en relación al principio de igualdad: «el principio de igualdad consagrado en el artículo $14 \mathrm{CE}$ hace referencia inicialmente a la universalidad de la ley, pero no prohíbe que el legislador contemple la necesidad o conveniencia de diferenciar situaciones distintas y de darles un tratamiento diverso, que puede incluso venir exigido, en un Estado social y democrático de Derecho, para la efectividad de los valores que la Constitución consagra con el carácter de superiores del ordenamiento como son la justicia y la igualdad» (STC 34/1981, FJ 3). En cualquier caso, en otras sentencias de esos primeros años se había referido el Tribunal a la generalidad como característica normal de la ley. Así, en la STC 6/1984, FJ 4, califica el «carácter general de la ley» como una «característica normal de la misma» por lo que «hemos de valorar si ésta es o no discriminatoria en términos de generalidad»; la STC 65/1985, FJ 3, aduce la generalidad como un carácter propio de la ley o la STC 42/1981, FJ 4, remitía a una «ley general del Estado» la regulación de las condiciones que garanticen la igualdad de todos los españoles en el ejercicio de los derechos constitucionales. De forma más tajante, el voto particular del magistrado Díez-Picazo en la STC 34/1981 considera que el principio de igualdad, al imponer la desaparición de los privilegios (privatae leges) exige, en consecuencia, la estructura general de la ley y el principio de universalidad. No es ésta, sin embargo, la doctrina de la STC 166/1986, FJ 10, que, como veremos después, parte de la «vocación a la generalidad que su propia estructura interna impone a las leyes» pero no es un «obstáculo insalvable» para el legislador.

Revista Española de Derecho Constitucional

ISSN-L: 0211-5743, núm. 104, mayo-agosto (2015), págs. 269-295

http://dx.doi.org/10.18042/cepc/redc.104.09 
rantía democrática, sino, por el contrario, una limitación de las garantías de los derechos e intereses legítimos que se asocian al control jurisdiccional de la actuación administrativa a las que de alguna forma suplanta. Esto nos sitúa en una perspectiva distinta a la mera defensa de la generalidad y abstracción como elementos propios de la ley que, ciertamente, puede ser matizada en una sociedad plural, heterogénea y conflictiva, difícilmente regulable sólo con normas de aplicación universal, siempre que ese tratamiento singular tenga una justificación objetiva y razonable. Se trata de mostrar los riesgos que conlleva para la situación jurídica de las personas, físicas y jurídicas, directamente afectadas por la ley singular no tanto la flexibilización de la generalidad y la abstracción sino su carácter de medidas formalmente legislativa y materialmente administrativas, que dificulta su control.

Desde esa perspectiva, la reciente doctrina del Tribunal Constitucional parece impedir en la práctica la figura no por su relación con el límite constitucional del principio de igualdad, al que se vincula su justificación como actuación excepcional, sino por no superar el parámetro de constitucionalidad de la tutela judicial efectiva. La consecuencia que parece derivarse de esta sentencia es la desaparición de las leyes singulares autoaplicativas (STC 129/2013) y la muy difícil aceptación de las restantes en cuanto limitan la tutela judicial efectiva (STC 203/2013). Si conciliamos la doctrina de ambas sentencias podemos afinar la argumentación: parecen impedirse las leyes singulares estrictamente autoaplicativas mientras las que permiten ulteriores actos administrativos de aplicación pueden seguir aceptándose con un carácter excepcional siempre que superen un estricto test de «razonabilidad, proporcionalidad y adecuación», que ya no se vincula únicamente al principio de igualdad, como en la STC 166/1986, sino también a la tutela judicial efectiva.

El relato de esta doctrina del Tribunal Constitucional sobre las leyes singulares es el objeto de estas páginas. Sin embargo, debemos apuntar desde el principio sus insuficiencias al abordar el fenómeno. Resulta adecuada la incorporación al canon de inconstitucionalidad de una concepción material de la tutela judicial efectiva, adicionable a la estrictamente procesal y al principio de igualdad que lo configuraban en la STC 166/1986. Sin embargo, el planteamiento que se hace de la tutela judicial como límite en las SSTC 129/2013 y 203/2013 no es, a mi juicio, adecuado. No resulta posible exigir la misma intensidad de control a la tutela de la ley por parte del Tribunal Constitucional que a la tutela del acto administrativo por los tribunales ordinarios en cuanto son procesos ontológicamente distintos. Desde ese presupuesto sólo cabría concluir la negación sumaria del fenómeno, no sólo de las leyes singulares autoaplicativas sino de cualquier ley singular en virtud de sus destinatarios o de su objeto. No 
es el planteamiento que se sostiene en estas páginas, pues las leyes de estructura singular van a seguir existiendo. Entendemos, en ese sentido, que los límites intrínsecos a la tutela de la ley a instancia de los directamente afectados pueden resultar compensados a través de un mayor control político-democrático, que, sin duda, permite esta fuente, y ha rechazado el Tribunal en la STC 129/2013. No se trata sólo de garantizar la tutela judicial efectiva del directamente afectado por una ley singular sino que deben exigirse especiales garantías democráticas cuando, excepcionalmente, el legislador actúa de esta forma. En esta situación es necesario configurar un modelo de control jurisdiccional de las leyes singulares que permita una tutela efectiva del ciudadano frente a la ley, aunque no sea en condiciones similares a la tutela frente al acto administrativo $y$, a su vez, refuerza el procedimiento de elaboración con garantías de participación y debate público. A partir de ahí emerge de nuevo el elemento garantista y democrático que caracteriza a la ley, adaptándose, obviamente, a la realidad actual. En ese sentido debe configurarse un concepto democrático de ley que tiene como pilares, por tanto, el control de sus efectos y de su procedimiento de elaboración.

Para desarrollar la tesis apuntada (que no puede agotarse en estas páginas) repasaré tanto la definición de ley singular en la doctrina del Tribunal Constitucional como su evolución, desde la construcción inicial de la STC 166/1986 a la STC 129/2013, con su antecedente en la STC 48/2005 y su importante epígono en la STC 203/2013. Parece claro que la definición de ley singular se mantiene pero los límites constitucionales han cambiado. En un primer momento procedía del principio de igualdad mientras que en la actualidad el derecho a la tutela judicial efectiva pretende convertirse en un límite casi infranqueable a las leyes singulares. La cuestión es relevante pues imposibilita la propia existencia de la figura, sin perjuicio de que se introduzcan modificaciones en el ordenamiento que hagan posible la garantía jurisdiccional directa del afectado frente a la ley. Por ello, como hemos explicado, no podemos ceñirnos a la asimilación en la tutela judicial. Estamos ante una ley, esto es, ante el monopolio de control del Tribunal Constitucional. No podemos aspirar a que la tutela brindada por el órgano constitucional de control se asimile a la que ofrece el órgano jurisdiccional ordinario, pero, por otro lado, precisamente esta fuente se caracteriza por exigir un mayor control democrático con la participación de las minorías en algún momento de su proceso de producción (F. Balaguer, 1992, 55-57). Por ello, parece necesario valorar la figura desde la perspectiva del control democrático de la ley pues, más allá de la garantía procesal que para la persona afectada por una ley singular significa el artículo 24.1 CE, refleja una concepción de la ley que tiende a soslayar su carácter democrático, de lo que deriva, a mi juicio, que, 
aun en los supuestos excepcionales en los que pueda dictarse, deberá exigirse el refuerzo de los elementos democrático-pluralistas en su procedimiento de elaboración.

\section{LAS LEYES SINGULARES EN LA DOCTRINA DEL TRIBUNAL} CONSTITUCIONAL: DE LA EXCEPCIONALIDAD A LA IMPOSIBILIDAD

\section{La configuración inicial en la STC 166/1986: el límite de la igualdad}

La STC 166/1986 nos aporta una definición de ley singular que continúa resultando válida para el Tribunal Constitucional en 2013. Nos dice el Tribunal que son leyes singulares «aquellas dictadas en atención a un supuesto de hecho concreto y singular, que agotan su contenido y eficacia en la adopción y ejecución de la medida tomada por el legislador ante ese supuesto de hecho, aislado en la ley singular y no comunicable con ningún otro» (STC 166/1986, FJ 10). Lo que cambia en las SSTC 129/2013 y 203/2013 es la manera de enfocar los límites a la figura. Como se advierte, el Tribunal no utiliza el criterio de la generalidad de los destinatarios, al que se opondría la singularidad, o determinación, de éstos sino el de la abstracción de los supuestos de hecho o conductas a las que se aplica, al que se opone la concreción de un objeto que se agota en su cumplimiento. En este sentido, no vamos a intentar una clasificación de todos los fenómenos que pueden incardinarse bajo la denominación de leyes singulares en cuanto carecen de los rasgos propios de la ley cuales son la generalidad y la abstracción (G. Ariño, 1989, 74-75; J. A. Montilla, 1994a, 125-127). La STC $203 / 2013$ se ha detenido en esta cuestión. Señala, como se ha apuntado, que en ese específico supuesto no se estaba ante una ley autoaplicativa en cuanto era susceptible de aplicaciones ulteriores, tampoco era una ley singular en virtud de sus destinatarios, pero sí atendiendo al objeto, en cuanto establece un supuesto de hecho determinado. Por tanto, una ley es singular cuando tiene destinatarios concretos o un supuesto de hecho determinado en el que agota su aplicación. $\mathrm{Y}$ es autoaplicativa cuando no precisa actos administrativos de aplicación para alcanzar su objeto, sino que los efectos jurídicos pretendidos derivan directamente de la norma legislativa. En realidad las leyes singulares son medidas legislativas materialmente administrativas, aun cuando puedan tener, e incluso requieran para su plena aplicación, otros actos aplicativos, como ocurre en el supuesto de la STC 203/2013. En estos casos se aplica la excepcionalidad y los límites derivados del principio de igualdad y de la tutela judicial efectiva, más allá del carácter general de las leyes restrictivas de derechos al que también se 
había referido la STC 166/1986. El principio de igualdad para justificar que ese tratamiento diferenciado, singular en el sujeto o el objeto, tiene una justificación objetiva y razonable y la tutela judicial efectiva en cuanto la medida normativa singular afecta bien directamente como destinatarios bien como vinculados al objeto singular que regula a determinadas personas que carecen de mecanismos de defensa jurisdiccional, directa e inmediatamente, al tratarse de una ley. En estas circunstancias, si la actuación legislativa no es sólo materialmente administrativa sino también estrictamente autoaplicativa parece inevitable su inconstitucionalidad, como nos explica la STC 129/2013, pues más allá de la flexibilización de la relación legislación-ejecución y de la justificación objetiva y razonable del tratamiento singular provoca la indefensión del directamente afectado en cuanto no tiene acceso a la jurisdicción para defenderse frente a la ley. Pero incluso si no lo es en sentido estricto, sino que se dirige a destinatarios concretos o regula un supuesto concreto en el que se agota su objeto, habrá que atender a los criterios de razonabilidad y proporcionalidad para justificar su utilización excepcional.

En este sentido, el rasgo esencial del fenómeno que nos ocupa, más allá de la relación generalidad-singularidad, es el carácter de medidas legislativas de naturaleza administrativa. Nos situamos ante fuentes con fuerza, rango y valor de ley dictadas con un concreto destinatario, al que limitan su alcance y/o en atención a un determinado supuesto de hecho, no comunicable a cualquier otro, en el que agotan su contenido y eficacia. En consecuencia, son actos formalmente legislativos que hemos identificado como leyes singulares por la relación medio-objeto que se establece. No crean un orden previo que permita el desarrollo ejecutivo a través de actos de aplicación susceptibles de control jurisdiccional, sino que son, en sí mismo, acción. Transforma el acto legislativo en acción legislativa. Son estas leyes singulares, las leyes medidas en la construcción alemana clásica (2), las que no pueden abordarse únicamente desde la perspectiva del principio de igualdad sino también desde la tutela judicial efectiva en cuanto al tratarse de una intervención del legislador en la función propia del ejecutivo exige un control similar al que los tribunales ejercen sobre los actos de la Administración (G. Ariño, 1989, 79), esto es, que atienda a su naturaleza administrativa más que a su forma legislativa, como ha terminado diciendo el Tribunal Constitucional en su reciente doctrina.

Inicialmente, en la STC 166/1986, el Tribunal Constitucional las había permitido sólo en casos excepcionales, en los supuestos en los que «por su extraor-

(2) Sobre el origen doctrinal de la ley medida en Alemania, remito mi trabajo Las leyes singulares en el ordenamiento constitucional español, págs. 131-136. 
dinaria trascendencia y complejidad, no son remediables por los instrumentos normales de que dispone la Administración, constreñida a actuar con sujeción al principio de legalidad, ni por los instrumentos normativos ordinarios, haciéndose por ello necesario que el legislador intervenga singularmente, al objeto exclusivo de arbitrar solución adecuada a una situación singular». A juicio del Tribunal, «la resistencia conceptual que, en principio suscitó esta clase de leyes se encuentra actualmente superada por la doctrina científica, según la cual el dogma de la generalidad de la ley no es obstáculo insalvable que impida al legislador dictar, con valor de ley, preceptos específicos para supuestos únicos o sujetos concretos. Ello no quiere decir, sin embargo, que las leyes singulares sean totalmente equiparables a las leyes generales en el sentido de que constituyan ejercicio normal de la potestad legislativa, sino que se configuran como ejercicio excepcional de esta potestad, subordinada a rigurosos límites» (FJ 10). Aquella sentencia se ocupaba de un supuesto singular tanto por el sujeto ( $\mathrm{Ru}-$ masa) como por el objeto (expropiación legislativa) pero también de carácter absolutamente excepcional. Así lo reconoce el propio Tribunal: "la expropiación del Grupo Rumasa es, según dice la STC 111/1983”, un caso singular, que no responde a esquemas generales, pero atiende a una situación de grave incidencia en el interés de la Comunidad, comprometido por el riesgo de estabilidad del sistema financiero y la preservación de otros intereses sociales que reclamaron, junto a una acción inmediata que no podía posponerse a la utilización de mecanismos legislativos ordinarios, la actuación global a través de la técnica expropiatoria. No resulta necesario entrar aquí en la naturaleza jurídica de esta técnica, sino señalar que la objetiva razonabilidad y proporcionalidad de la singularidad de la expropiación, así como de su causa expropiandi está reconocida y declarada en dicha sentencia, legitimadas en una situación excepcional que reclamaba una acción de los poderes públicos, por cuanto ante la dimensión del fenómeno con proyección en el orden económico y financiero, y aun en el social por la extensión de los sectores afectados, el problema tenía una relevancia que traspasaba las fronteras de los acotados límites de una crisis empresarial para convertirse en un factor determinante de inestabilidad de la situación financiera nacional» (FJ 14).

A partir del carácter excepcional de las leyes singulares, sometidas a rigurosos límites, la sentencia pionera del Tribunal Constitucional sobre las leyes singulares (STC 166/1986) analiza esos límites. En primer lugar, se detiene en la reserva de administración, en cuanto esa actuación tiene, como hemos señalado ya, naturaleza administrativa. La quiebra de la generalidad abre la posibilidad de que el legislativo invada otras funciones frente a lo que se ha planteado una reserva de administración. En cualquier caso, considera el Tribunal que la

Revista Española de Derecho Constitucional 
Constitución no contiene en su artículo $97 \mathrm{CE}$ una reserva de administración, de modo que cabe hablar, «salvo en reservas materiales de ley o en actividades de pura ejecución, de una cierta fungibilidad entre el contenido de las decisiones propias de cada una de dichas funciones», esto es, los órganos legislativos pueden adoptar, aunque sea con carácter excepcional, decisiones típicamente ejecutivas (FJ 4). También se ocupa del límite que supone el carácter general de las leyes restrictivas de derechos fundamentales. Estamos ante la directa influencia de la Constitución alemana que incluye expresamente ese límite en su artículo 19.1 al indicar que «cuando de acuerdo con la presente Ley Fundamental un derecho fundamental pueda ser restringido por ley o en virtud de una ley, ésta deberá tener carácter general y no ser limitado al caso individual».

Pero, sin duda, el límite relevante que, a juicio del Tribunal, deben superar las leyes singulares es el del principio de igualdad en cuanto viene a cubrir las funciones clásicas de la generalidad y se vincula directamente con la excepcionalidad del supuesto. En ese sentido, el Tribunal ha admitido las leyes singulares expropiatorias por considerar que no infringían el principio de igualdad si la excepcionalidad o singularidad del supuesto de hecho para el que se aprobaba la ley justificaba razonable y proporcionadamente la divergencia introducida, en este caso, en el procedimiento expropiatorio. La regla general es que el principio de igualdad impone a las leyes una vocación de generalidad, pero la igualdad no impide la diferenciación normativa sino que exige a ésta una justificación objetiva y razonable, lo que obliga a un análisis de la razonabilidad y proporcionalidad de la medida legislativa: objetivamente justificada y proporcionada al fin que se persigue (3). Por ello, es posible que ante un supuesto concreto se dicte una ley singular, siempre que dicho supuesto así lo exija. El límite del principio de igualdad exige que la ley singular responda a una situación excepcional igualmente singular: «Esto equivale a decir que la prohibición de desigualdad arbitraria o injustificada no se refiere al alcance subjetivo de la norma sino a su contenido y, en su virtud, que la ley singular debe responder a una situación excepcional igualmente singular y que su canon de constitucionalidad es la razonabilidad y proporcionalidad de la misma al supuesto de hecho sobre el que se proyecta» (FJ 11). La razón determinante de la razonabilidad y proporcionalidad es la trascendencia del supuesto concreto para la propia estabilidad financiera nacional, a lo que nos hemos referido más atrás.

(3) En el supuesto de las leyes singulares expropiatorias debe respetarse también el marco del artículo $33 \mathrm{CE}$, en concreto, debe responder a un hecho singular o extraordinario, prever la indemnización correspondiente y las singularidades procedimentales que se establezcan serán acordes con la singularidad del supuesto de hecho que justificó la expropiación (FJ 13). 
Más sorprendente era la interpretación del Tribunal Constitucional en relación a la lesión de la tutela judicial efectiva del afectado por una ley singular. La STC 166/1986 considera que en este supuesto se produce una innegable limitación de la tutela judicial efectiva en cuanto los ciudadanos afectados por la expropiación se ven privados de la acción judicial que tendrían si hubiese sido declarada por acto administrativo, pero, a juicio del Tribunal Constitucional, esto no significa que queden radicalmente indefensos. El juez que plantea la cuestión de inconstitucionalidad origen de esta sentencia lo explicaba con claridad al elevar la cuestión que dio lugar a la sentencia. A su juicio, la categoría de ley formal que tienen los preceptos cuestionados, no susceptibles de control jurisdiccional por el principio de sometimiento de los tribunales y los jueces al imperio de la ley, impide a los expropiados recabar la tutela judicial de sus derechos de propiedad frente a la expropiación y necesidad de la ocupación, dejándolos indefensos con vulneración del artículo 24 CE (FJ 1). Sin embargo, el Tribunal Constitucional entiende que los afectados podrán alegar la violación del principio de igualdad ante cualquier acto material de ocupación, atendiendo a la discriminación producida por el tratamiento jurídico diferenciado anejo a la estructura singular de la ley si carece de una justificación objetiva y razonable. De esta forma inician el procedimiento correspondiente y pueden impugnar el acto legislativo que ha originado directamente la lesión en dos vías alternativas: en primer lugar, pueden solicitar al órgano judicial la elevación de una cuestión de inconstitucionalidad, con lo que queda satisfecho el derecho instrumental a la tutela judicial efectiva porque el juez elevará la cuestión o la denegará, otorgando contenido, en ambos casos al derecho a la tutela judicial; o, en segundo lugar, podrán plantear, agotada la vía judicial previa, un recurso de amparo constitucional, al margen de que el derecho materialmente afectado sea susceptible de amparo constitucional, por la supuesta violación del artículo $14 \mathrm{CE}$. Esto significa, en definitiva, que el Tribunal acepta que el particular no pueda recurrir directamente la ley singular por la que resulta afectado sin que ello suponga vulneración del derecho a la tutela judicial efectiva. Son evidentes las limitaciones de esta tutela de la ley en cuanto el planteamiento de la cuestión resultaba ajeno a la voluntad del interesado y el recurso de amparo no puede plantearse frente a la ley y requiere la vulneración de un derecho fundamental de los susceptibles de amparo. Sin embargo, en esta sentencia, a diferencia de lo que ocurrirá luego en las SSTC 48/2005, 129/2013 o 203/2013, el Tribunal Constitucional se conforma con estas posibilidades mediatas de acceso a la jurisdicción. Ciertamente, esta posición fue cuestionada en el voto particular del magistrado Rubio Llorente al considerar que «en nuestro Derecho ni la jurisdicción constitucional forma parte del Poder Judicial, ni cabe el recurso de amparo frente a leyes, ni

Revista Española de Derecho Constitucional 
puede reducirse el derecho fundamental a la tutela judicial efectiva a la posibilidad de pedir al juez que plantee ante el Tribunal Constitucional la cuestión de inconstitucionalidad». En definitiva, el problema estriba en que la privación de medios ordinarios de defensa del ciudadano, que no pueden ser ejercidos frente a la ley, provoca indefensión. El afectado no puede acudir a los tribunales ordinarios porque la jurisdicción ordinaria no enjuicia una ley, cuyo monopolio de control ha sido asumido en nuestro ordenamiento por el Tribunal Constitucional; ni pueden acudir directamente a este Tribunal porque el proceso que regula en defensa de los derechos fundamentales directamente accionable por el particular no puede dirigirse contra un acto legislativo y los procesos contra leyes no pueden ser accionados directamente por el particular (J. A. Montilla, 1994b, 296). Éste es el problema. Las leyes singulares pueden superar el test del principio de igualdad, pues el tratamiento diferenciado singular puede tener una justificación objetiva y razonable en supuestos excepcionales pero les resulta más difícil superar el de la tutela judicial efectiva.

El Tribunal Europeo de Derechos Humanos vino a incidir sobre esta cuestión, siquiera de forma implícita, cuando en su sentencia de 23 de junio de 1993 (Rumasa contra España) condena al Estado español por violación del artículo 6.1 de la Convención Europea de Derechos Humanos en cuanto no sólo la acción de los demandantes en restitución de sus bienes no se había consumado en un plazo razonable, sino, en lo que a nosotros nos interesa, «el procedimiento de examen de las cuestiones de inconstitucionalidad planteadas por los tribunales civiles ha desconocido su derecho a un proceso equitativo». En definitiva, el Tribunal destaca lo que ya habían indicado tanto el voto particular del magistrado Rubio Llorente como la doctrina: para satisfacer la tutela judicial no basta con los cauces indirectos para acceder al Tribunal Constitucional. Pero ante esta insuficiencia de los cauces procesales-constitucionales frente a las leyes singulares no resulta suficiente una interpretación extensiva de los preceptos que regulan la cuestión de inconstitucionalidad para permitir la presencia de las partes, como ha hecho la LO 6/2007. La condena al Estado español por la incomparecencia de los afectados en el procedimiento de la cuestión de inconstitucionalidad tiene su origen último en la inexistencia de una vía procesal que permita el acceso directo del ciudadano al Tribunal Constitucional para defenderse de estos actos legislativos de naturaleza administrativa que afectan directamente a sus derechos e intereses legítimos. Por ello, en 1994 sostuve que «la conciliación de la ley singular de intervención y el derecho instrumental a la tutela judicial efectiva de los derechos e intereses legítimos no puede limitarse a la interpretación flexible de los procesos constitucionales, sino que impetra el reconocimiento legislativo procesal de un recurso directo de inconstitucio- 
nalidad, planteable por el ciudadano, mediante el cual impugne en un procedimiento concreto ante el Tribunal Constitucional el acto legislativo, asegurando el control de constitucionalidad de una ley que afecta de forma inmediata su situación jurídica subjetiva» (J. A. Montilla, 1994b, 316).

Ahora, al hilo de la STC 129/2013, vuelve a reclamarse la incorporación a nuestro ordenamiento de ese amparo directo frente a leyes (J. M. Díaz Lema, 2013, 72-73). Sin embargo, aun manteniendo la existencia de esa laguna no podemos pensar que con cubrirla queda resuelto el problema en la utilización de la ley singular que reflejan los supuestos de hecho de las SSTC 129/2013 y 203/2013. La respuesta reclamada frente a una expropiación legislativa singular resulta insuficiente para abordar los casos en los que el legislador utiliza el instrumento normativo de la ley para soslayar el control jurisdiccional de la decisión política. Y ello porque el acceso de los particulares al control de constitucionalidad de la ley no asimila el control jurisdiccional de las leyes singulares al que tendrían si fueran actos administrativos como corresponde a su naturaleza de medidas. La cuestión de inconstitucionalidad no faculta el control directo, sino, a lo sumo, la solicitud de control y a través del amparo sólo se controla la hipotética vulneración de un derecho fundamental, que la propia STC 166/1986 vincula al carácter discriminatorio del tratamiento singular. Sin embargo, no permite controlar la afectación sustantiva de los intereses legítimos contraria al ordenamiento, sin que conlleve específica vulneración de un derecho fundamental. Por tanto, aun incorporando mecanismos de control de la ley por el Tribunal Constitucional a instancia de los afectados, no se producirá esa asimilación.

\section{El reconocimiento de la tutela judicial efectiva como límite infranqueable para las leyes singulares}

Como se ha dicho, si ya en el debate desarrollado durante el pasado siglo a propósito del caso Rumasa se ponía de manifiesto la difícil conciliación de las leyes singulares y el derecho a la tutela judicial efectiva, en los últimos años ha sido el propio Tribunal Constitucional quien, matizando su posición anterior, configura este derecho instrumental en la práctica como un límite infranqueable a las leyes singulares.

El punto de inflexión lo encontramos en la STC 48/2005. En este supuesto, el Tribunal Constitucional ya no se refiere a la vertiente puramente procesal del artículo $24 \mathrm{CE}$, sino al contenido material o tutela material propia de este derecho, cuando impone un control jurisdiccional de mayor alcance y densidad (J. Ortega, 2007, 299). Se enjuiciaba en este caso una ley autonómica canaria que 
pretendía la expropiación de distintos edificios para construir el Parlamento de Canarias. Ante este supuesto de hecho singular el Tribunal valora su excepcionalidad para concluir que la expropiación debatida es «una situación nada fuera de lo corriente», que no justificaba, por tanto, la utilización de una ley. Aparece incluso la razón material de la actuación: no habiendo un acuerdo con los propietarios del inmueble se acude a la ley singular. Sin embargo, no es ésa la cuestión decisiva para el Tribunal en este caso sino directamente la tutela jurisdiccional «material». A juicio del Tribunal, deberá tutelarse la posición jurídica de los afectados por la expropiación legislativa, con independencia de que dicha tutela sea proporcionada por la jurisdicción ordinaria o por la constitucional. Pero, además, si la tutela la ofrece la justicia constitucional, al tratarse de una ley, debiera ser «equivalente» a la que brindaría el juez de lo contencioso en el caso que se hubiera hecho la expropiación a través de un acto administrativo. Esto significa que ya no basta con constatar que existen mecanismos procesales, siquiera indirectos, que permiten el control de la actuación singular del legislador, lo que determina el alcance puramente procesal de la tutela, sino que el Tribunal Constitucional se adentra en el efectivo contenido material de ese control para mostrar su insuficiencia.

Por tanto, a partir de esta sentencia la principal objeción que se puede realizar a las leyes singulares es la limitación de la tutela judicial efectiva. Nos lo explica la STC 48/2005 con meridiana claridad: «un acto legislativo expropiatorio sólo será constitucionalmente admisible si el control jurisdiccional que admiten las normas con rango de ley (recurso directo, cuestión y autocuestión; esta última previo amparo) es suficiente, en cada caso, para brindar una tutela materialmente equivalente a la que puede dispensar frente a un acto administrativo un juez de lo contencioso. Por tanto, la forma legislativa únicamente será admisible si todas las lesiones que eventualmente le sean imputables pueden corregirse con el normal ejercicio de la jurisdicción constitucional, sin desnaturalizarla o pervertirla para, forzando su naturaleza, extenderse también sobre extremos de la disposición que sólo están al alcance de la jurisdicción ordinaria» (FJ 6).

Como apuntábamos más atrás, el planteamiento del Tribunal es una aporía, pues en ningún caso puede ser equivalente el control de constitucionalidad ejercido por el Tribunal Constitucional y el control jurisdiccional ordinario. Frente a la ley singular se pueden garantizar los derechos fundamentales, a través de procedimientos no previstos pero de posible incorporación al ordenamiento. Sin embargo, los intereses legítimos afectados por la ley no pueden ser valorados en el control de constitucionalidad más allá de enjuiciar la justificación objetiva y razonable del tratamiento singular, aun cuando se incorporen «elementos de evaluación que resultan impropios de la jurisdicción de este TC» (FJ 7). 
En consecuencia, la STC 48/2005 nos señala que más allá del necesario carácter realmente excepcional del supuesto de hecho objeto de la ley singular se debe garantizar la tutela judicial desde una perspectiva material, no sólo formal, lo que significa que el control sea equivalente al que brindaría en el caso de un acto administrativo. Esta nueva doctrina es la que consolida y desarrolla la STC $129 / 2013$.

El asunto que dio lugar a la STC 129/2013 era la primera ocasión en la que el TC debía ocuparse de una ley singular no expropiatoria. El TC entiende que la garantía del derecho a la tutela judicial efectiva no puede quedar limitada a leyes autoaplicativas expropiatorias, pues también otras pueden ser susceptibles de lesionar derechos e intereses legítimos. Se equiparan las situaciones de los sujetos expropiados con las de otras personas aunque tan sólo pudieran invocar intereses legítimos o, incluso, intereses simples amparados por el reconocimiento de acción popular en determinados sectores, como el urbanismo o la ordenación del territorio (R. J. Santamaría, 2014, 180). No se trata de meras leyes singulares de aprobación o autorización, pero tampoco son, en sentido estricto, leyes singulares de intervención. Son, en definitiva, medidas materialmente administrativas que adoptan la forma de ley.

Pero lo realmente novedoso es que el Tribunal se enfrenta directamente a la razón material de la actuación del legislador, que pretende evitar el control de la medida dándole forma legislativa. Se utiliza la soberanía del legislador para evitar el control de la jurisdicción contencioso-administrativa, pudiendo provocar la indefensión de los directamente afectados por estas leyes autoaplicativas. En definitiva, el Tribunal afronta las consecuencias que en su utilización práctica ha generado la eliminación, siquiera con carácter excepcional, de los rasgos tradicionales de la ley: la conversión de la ley en mecanismo de defensa de intereses concretos al servicio del poder político, evitando el control jurisdiccional de su actuación.

Ciertamente, el TC había permitido en alguna ocasión la interferencia del legislador en procesos judiciales, como en la STC 73/2000 (Itóiz). La cuestión de inconstitucionalidad se plantea en este caso por entender la Sala de lo contencioso de la Audiencia Nacional que la modificación de la Ley foral navarra 6/1987, sobre protección y uso del suelo no urbanizable se habría aprobado para hacer inaplicable la declaración de nulidad e impedir la ejecución de una sentencia del Tribunal Supremo que anulaba parcialmente el proyecto de construcción del embalse de Itóiz. Sin embargo, el TC entiende que no estamos ante una ley singular sino ante un simple cambio normativo producido durante la tramitación de un recurso judicial (J. M. Díaz Lema, 2013, 66). 
No obstante, en la STC 129/2013 rechaza frontalmente esta actuación. A juicio del Tribunal, el supuesto enjuiciado en esta sentencia constituye un uso de la ley por parte del poder político para evitar las dificultades que la jurisdicción podía poner a una determinada actuación. Tras los obstáculos jurisdiccionales en supuestos similares, con anulación del Decreto que había aprobado un proyecto regional, se utiliza el atajo de aprobar una ley singular sobre declaración de proyectos regionales de infraestructura de residuos de singular interés para la comunidad (R. J. Santamaría, 2014, 169). En el Preámbulo de la Ley se explica que «la concurrencia de condicionantes supralocales o supraprovinciales puede constituir un motivo de interés singular para la comunidad más allá del interés al que se refiere la Ley de Ordenación del Territorio, lo que requiere en estos casos que la Declaración de Proyecto Regional se lleve a cabo directamente por el Poder Legislativo». A partir de ahí, la propia Ley describe el «primer supuesto de aplicación» que es el de las «instalaciones del centro de transferencia, planta de tratamiento físico-químico y depósito de seguridad que existen en la localidad de Santovenia de Pisuerga, en la provincia de Valladolid». De esta forma, como indica el TC, la Disposición Adicional Primera de la Ley «contiene una ley singular de autoaplicación de la ley general en la que formalmente, aunque no necesariamente, se ha enmarcado. En definitiva, la Disposición Adicional contiene una ley autoaplicativa que sustituye, por expreso mandato del artículo único, la actividad administrativa de aplicación de la ley general» (FJ 3).

A partir de la consideración de esta actuación legislativa como ley singular, el TC recoge la doctrina de la STC 166/1986 sobre la definición de ley singular, en la que se encuadra sin dificultad este supuesto, y sobre la inexistencia de una reserva de administración de forma que se permite, siquiera con carácter excepcional por la aplicación de límites constitucionales, la aprobación de actos legislativos de naturaleza administrativa a partir de la flexibilidad o fungibilidad de las funciones legislativa y ejecutiva. Sin embargo, el límite infranqueable lo establece en relación a la tutela judicial efectiva, reforzando la doctrina de la STC 48/2005. En concreto el Tribunal considera que:

a) Los interesados deben poder acceder al TC reclamando el control de constitucionalidad de la norma singular. Como hemos visto, en la STC 166/1986 el requisito de acceso se había relativizado al admitir para su satisfacción simplemente la posibilidad de instar ante el juez el planteamiento de la cuestión de inconstitucionalidad. Debe recordarse, en este sentido, que conforme al artículo 37.2 LOTC, en la redacción dada por la LO 6/2007, quienes sean parte en el procedimiento judicial de origen pueden personarse ante el TC y formular alegaciones. Sin embargo, esta previsión, que seguramente permite responder a la condena de España por el TEDH en el asunto Rumasa, no supone una garantía 
de control jurisdiccional de la ley autoaplicativa a instancias del afectado. En este sentido, la cuestión de inconstitucionalidad no satisface el derecho a la tutela judicial efectiva porque el planteamiento de la cuestión es una prerrogativa exclusiva del juez pero no un derecho del justiciable. Los titulares de derechos e intereses legítimos «carecen de un recurso directo contra las leyes autoaplicativas», únicamente pueden solicitar al juez el planteamiento de la cuestión. Por todo ello concluye que «el artículo $24 \mathrm{CE}$ exige que su titular pueda instar la tutela que el precepto consagra, requisito éste que no se cumple en el caso de las leyes autoaplicativas en las que el planteamiento de la cuestión es una prerrogativa exclusiva del juez, pero no un derecho del justiciable» [FJ 6, a)].

b) Pero, además, en segundo lugar, el TC sostiene que el derecho a la tutela judicial requiere del tribunal un control de la medida controvertida de la misma intensidad que si se tratara de un control en la vía contencioso-administrativa, esto es, el control que realice el TC debe ser suficiente para brindar una tutela materialmente equivalente a la que pueda otorgar, frente a un acto administrativo, la jurisdicción contencioso-administrativa (STC 48/2005) (FJ 5), pues en modo alguno la reserva de ley puede servir como instrumento dirigido a evitar o disminuir la protección de los derechos e intereses legítimos amparados por la legislación ordinaria. Por tanto, no basta con poder acceder, habrá que utilizar como parámetro también la intensidad del control que puede ejercer el TC. No obstante, el Tribunal es consciente de que la reserva al legislador de la aplicación de la legalidad existente al caso concreto, con exclusión de la actividad que ordinariamente realiza la Administración, impide un control de la misma intensidad el que correspondería realizar a los tribunales de la jurisdicción contencioso-administrativa, si la actividad de ejecución se hubiera llevado por la Administración. En modo alguno corresponde al TC el control fáctico y de legalidad ordinaria (control de los elementos reglados del acto de aplicación), que, en todo caso, exige la función de aplicación de la norma al caso concreto, con independencia de quién la lleve a cabo (FJ 6).

En consecuencia, conforme a estos criterios, el TC declara la inconstitucionalidad de la DA primera de la Ley 9/2002, de Castilla y León, pues contiene una ley autoaplicativa que vulnera el derecho fundamental a la tutela judicial efectiva de los derechos e intereses legítimos afectados.

La diferencia con la STC 166/1986 es que en ese supuesto el Tribunal Constitucional salvaba la constitucionalidad de la ley desde la perspectiva de la tutela judicial efectiva aduciendo los cauces mediatos que podría instar el interesado para que la ley singular fuera enjuiciada por el Tribunal Constitucional. Sin embargo, ahora, como en la STC 48/2005, se constata la inexistencia de cauces procesales que puedan ofrecer una garantía «equivalente», o de la misma inten-

Revista Española de Derecho Constitucional 
sidad, a la que derivaría de los órganos jurisdiccionales ordinarios y se declara la inconstitucionalidad. Aunque la STC 129/2013 dice que «en consecuencia, el canon de constitucionalidad que debe utilizar este Tribunal al ejercer su función de control de este tipo de leyes es el de la razonabilidad, proporcionalidad y adecuación», en la práctica el análisis se centra en la «repercusión de la ley singular cuestionada sobre el derecho fundamental a la tutela judicial efectiva»y resulta imposible superar este test por su propio carácter autoaplicativo, pues no existen mecanismos para defenderse frente a la ley e incluso, aunque éstos se incorporen al ordenamiento a través del amparo frente a leyes en ningún caso pueden ser de la misma intensidad que los ofrecidos por la jurisdicción ordinaria.

Con esta sentencia, el Tribunal Constitucional parecía consolidar una nueva doctrina sobre las leyes singulares, atisbada en la anterior STC 48/2005, que, inicialmente, no sólo obliga a que se aborden los cambios en la LOTC reclamados en la doctrina desde la polémica sobre el caso Rumasa, sino que impide la propia existencia de estas leyes singulares autoaplicativas por la imposibilidad de garantizar la tutela judicial efectiva en estos supuestos. Aun incorporando procedimientos de acceso directo al Tribunal Constitucional frente a una ley singular autoaplicativa por parte de los afectados siempre estará la exigencia de igual «intensidad» o «equivalencia material» del control jurisdiccional, imposible de satisfacer por el Tribunal Constitucional (4).

En ese contexto, la STC 203/2013 introduce algunos matices en esa doctrina. En este caso, para evitar que el proyecto denominado «Ciudad del Medio Ambiente» se paralizase en virtud de decisiones judiciales, se aprueba la Ley 6/2007, de aprobación del proyecto regional Ciudad del Medio Ambiente. Entiende el TC que «se trata, junto a las leyes de destinatario único y las leyes autoaplicativas, de un género de la ley singular», "cuando la utilización de la ley obedece única y exclusivamente a una situación excepcional, el legislador debe estar sujeto a los mismos límites constitucionales que el resto de leyes singulares que han sido dictadas en atención a un supuesto de hecho excepcional que las justifica. Tanto más, si cabe, cuando la situación excepcional a la que responde la ley incide de forma directa, aunque no necesariamente ilegítima, en el derecho a la tutela judicial efectiva, pues la aprobación por ley impide el control de la jurisdicción contencioso-administrativa a que se someten el resto

(4) Tiene razón R. J. SANTAMARÍA ARINAS cuando afirma al hilo de la STC 129/2013, sin tener en cuenta la STC 203/2013 que «aparentemente se mantiene la afirmación de que las leyes singulares autoaplicativas no están prohibidas en el sistema constitucional español. Pero resulta una afirmación retórica si se tiene en cuenta que esa posibilidad se rodea de límites cada vez más estrechos» (cit., pág. 189).

Revista Española de Derecho Constitucional

ISSN-L: 0211-5743, núm. 104, mayo-agosto (2015), págs. 269-295

http://dx.doi.org/10.18042/cepc/redc.104.09 
de planes urbanísticos regionales que, por carecer de dicha excepcionalidad, son aprobados por el Consejo de Gobierno. En consecuencia, el canon de constitucionalidad que habría de aplicarse es el establecido en la doctrina constitucional para las leyes de esta naturaleza, con las particularidades que derivan de las especiales características de este género de leyes singulares, que no son ni de destinatario único ni autoaplicativas (FJ 3).

En este caso, la ley singular, al no ser estrictamente autoaplicativa, no se declara directamente inconstitucional, sino que, al menos formalmente, se somete al test de razonabilidad y proporcionalidad. En este sentido, el Tribunal considera justificado el carácter excepcional del desarrollo urbanístico previsto en la Ley en cuanto su importancia para el desarrollo social y económico de la Comunidad Autónoma responde a razones objetivas apreciadas por el legislador (FJ 6). Por tanto, existe una justificación objetiva. Sin embargo, esa justificación no es razonable y proporcionada. Por un lado, «el legislador no ha explicitado las razones por las que entiende que la utilización de la ley es una medida razonable y proporcionada, aun a sabiendas de que, tal y como se puso de manifiesto en el debate legislativo, la utilización de la ley eliminaba el control de la jurisdicción contencioso-administrativa», «no consta en modo alguno en el proyecto la inaplicación de norma legal o reglamentaria alguna, por lo que la misma ordenación podría haberse abordado mediante una norma aprobada por el Consejo de Gobierno». [...] «La utilización de la ley ha sacrificado el control de legalidad ordinaria a la que el proyecto afirma responder, un control que hubiera correspondido realizar a la jurisdicción contenciosoadministrativa - recurso directo o indirecto contra reglamento - a instancias de los titulares de derechos e intereses legítimos, o de la acción pública reconocida en materia de urbanismo y medio ambiente.» En fin, «la aprobación por ley de este planteamiento urbanístico ha impedido que los tribunales de la jurisdicción contencioso-administrativa puedan controlar la legalidad de la nueva clasificación del suelo, la adecuación del proyecto a la evaluación del impacto ambiental y la legalidad misma de la evaluación ambiental, control jurisdiccional al que se hubiera tenido acceso si la norma hubiera sido aprobada por el Consejo de Gobierno»».

Por tanto, aunque en este segundo supuesto la inconstitucionalidad no deriva directamente de la naturaleza de la ley, sino de aplicación del test de razonabilidad, es difícil imaginar un supuesto de ley singular en el que la respuesta del Tribunal Constitucional sea distinta, pues el límite ya no es el principio de igualdad, sino una actuación de naturaleza administrativa al margen de los «instrumentos normales de que dispone la Administración» que, por ello, vulnera el artículo $24 \mathrm{CE}$ al «impedir el acceso al control judicial de derechos e intereses 
legítimos afectados y eliminar la posibilidad de un control judicial de la misma intensidad que hubieran podido realizar los tribunales de la jurisdicción si el proyecto se hubiera aprobado por reglamento» (5).

La diferencia entre los supuestos de la STC 129/2013 y la STC 203/2013 es que en el primer caso estamos ante una ley autoaplicativa, un acto administrativo en sentido estricto con forma de ley cual es la autorización ope legis del centro de residuos de Santovenia mientras que en el otro estamos ante una ley singular en virtud de su objeto, la regulación de la Ciudad del Medio Ambiente, que permite actos de aplicación. Sin embargo, aunque formalmente la conclusión que podemos extraer al cotejar la doctrina del Tribunal Constitucional en ambas sentencias es que las leyes singulares estrictamente autoaplicativas, esto es, las leyes que sustituyen la actividad administrativa de aplicación de la ley general, no tienen cabida en nuestro ordenamiento y las leyes singulares en virtud del destinatario o del objeto, materialmente administrativa pero que permiten actos de aplicación, tienen un carácter excepcional y deben ser sometidas a un estricto control de razonabilidad, proporcionalidad y adecuación (6) resulta prácticamente imposible la constitucionalidad de leyes singulares si el límite es la exigencia de una tutela judicial de igual intensidad o materialmente equivalente, pues el Tribunal Constitucional, como órgano de control de la ley, no puede ofrecer, por su propia naturaleza, una tutela asimilable a la que brinda la jurisdicción ordinaria.

\section{LAS LEYES SINGULARES EN EL MARCO DE LA NUEVA DOCTRINA DEL TRIBUNAL CONSTITUCIONAL}

No resulta sorprendente que tras estas sentencias se haya afirmado que las leyes singulares han quedado impedidas en nuestro ordenamiento, pues así resultaría en la práctica de una aplicación rigurosa de esta doctrina del Tribunal Constitucional. Sin embargo, ante el uso de las leyes singulares, autoaplicativas

(5) En la misma línea se había pronunciado el Tribunal de Justicia de la Unión Europea en su Sentencia de 18 de octubre de 2011 (Boxus v. Valonia) cuando considera que los proyectos con especial repercusión sobre el medio ambiente aprobados por el legislador en lugar de por la Administración deben someterse a un órgano jurisdiccional que pueda dejar sin aplicación dicho acto legislativo.

(6) Recuérdese que en la STC 166/1986, la proporcionalidad de la actuación legislativa se vinculaba a la situación excepcional que reclamaba una acción de los poderes públicos por la incidencia del fenómeno en el orden económico, financiero y social, factor determinante de la inestabilidad financiera.

Revista Española de Derecho Constitucional

ISSN-L: 0211-5743, núm. 104, mayo-agosto (2015), págs. 269-295

http://dx.doi.org/10.18042/cepc/redc.104.09 
o no, para limitar el control jurisdiccional a instancia de los afectados no podemos limitarnos al rechazo de un fenómeno que, aun de forma excepcional, puede atender en determinadas circunstancias a las necesidades de una sociedad plural y heterogénea, como se apuntaba al inicio. Por ello, el Tribunal Constitucional no debería haber configurado las bases para su eliminación sino para evitar su uso contrario a los principios y derechos constitucionales. En este sentido, debe reforzarse el control jurisdiccional para que el afectado por la ley singular pueda incoar su tutela ante el Tribunal Constitucional. Pero, como se decía al inicio, no basta con ello, pues el análisis de los supuestos enjuiciados en los últimos años por el Tribunal Constitucional muestra que la limitación de las garantías jurisdiccionales no es simplemente una consecuencia del uso de una fuente con un singular régimen de control jurisdiccional, sino que responde precisamente a la voluntad de soslayar ese control. En ese sentido, más allá de la mejora de los mecanismos de control jurisdiccional, con limitaciones ínsitas a la propia naturaleza de esta fuente, resulta necesario también el refuerzo de las garantías democráticas características de la ley en el procedimiento de elaboración, en concreto de la intervención plena del órgano parlamentario como institución más legitimada para garantizar el interés general.

En realidad, el debate sobre las leyes singulares no se plantea en la actualidad en relación a la estructura subjetiva u objetiva de ley, esto es, en la singularización de los destinatarios o del supuesto de hecho sino precisamente en la función de la ley en la crisis del Estado social y democrático de Derecho. No se trata de averiguar los destinatarios específicos de la ley o las veces que puede ser aplicada sino la finalidad del legislador cuando prescinde de su carácter general y abstracto y de su vocación de permanencia para incluir medidas legislativas de naturaleza administrativa. La respuesta primera a esa forma de actuar es la interposición de límites constitucionales pero, más allá de esto, nos obliga a preguntarnos por su incidencia en el propio concepto de ley.

Por ello, a partir de estos presupuestos lo que nos ocupa hoy es la utilización de la ley, cauce de expresión de la soberanía, por la mayoría parlamentaria para suplantar a la Administración a fin de evitar el control jurisdiccional de la medida política que contiene. Resulta paradójico que la ley, expresión del pluralismo social en cuanto permite la participación de las minorías en el proceso decisorio, se utilice para limitar las garantías de los afectados por sus medidas.

Sin embargo, esa paradoja se desvanece si partimos de que la quiebra de los caracteres tradicionales de la ley en el contexto de la crisis del Estado social supone la eliminación de las garantías que conlleva desde el Estado liberal. Es decir, la problemática que plantean en la actualidad las leyes singulares es una consecuencia de la concepción de la ley en la crisis del Estado social. 
Hemos comprobado sus dos características esenciales. En primer lugar, la ley ya no contiene siempre una regulación general y abstracta, sino que, a menudo, incorpora medidas de aplicación directa, suplantando a las instancias aplicativas. En segundo lugar, también en relación al origen y procedimiento de elaboración ya no representa a la voluntad general con participación de las minorías sino al legislador mayoritario que impone su decisión a través de un procedimiento condicionador del debate público y la participación de las minorías a través de fuentes legales gubernamentales o restricción del debate parlamentario. Hasta aquí hemos visto el problema de las garantías jurisdiccionales para atender al primer rasgo, pero no podemos soslayar las garantías políticas que también se han perdido con esta forma de legislar y deben recuperarse, pues son precisamente las definitorias de la ley en el sistema de fuentes del Derecho.

En este sentido, la respuesta debe producirse en dos direcciones. En primer lugar, deben incorporarse las modificaciones necesarias al ordenamiento para hacer posible la tutela directa frente a la ley ante el Tribunal Constitucional, aun no asimilable a la que ofrece la jurisdicción contencioso-administrativa frente a un acto administrativo de aplicación. Pero, por otro lado, deben exigirse garantías democráticas y de participación cuando se acuda a esta forma de legislar.

\section{La tutela de las leyes singular a instancia del afectado: el amparo frente a leyes}

Se ha dicho que cuando menos la doctrina de la STC 129/2013 puede suponer la obligación del juez o Tribunal de plantear la cuestión de inconstitucionalidad en el caso de leyes singulares, justifica un régimen jurídico especial con el reforzamiento de la iniciativa del particular (J. M. Díaz Lema, 2013, 72). En cualquier caso, es evidente que «suscitar la cuestión de inconstitucionalidad es una prerrogativa exclusiva e irrevisable del órgano judicial, el cual por el mero hecho de no plantearla y de aplicar la ley que no estima inconstitucional no lesiona, en principio, derecho fundamental alguno» (STC 129/2013, FJ 6). Por tanto, la tutela judicial no puede quedar satisfecha con la solicitud de planteamiento de una cuestión de inconstitucionalidad.

Por ello, para habilitar la tutela frente a la ley singular del afectado debe preverse un amparo directo vinculado, lógicamente, a la vulneración de un derecho fundamental. En este sentido, debe modificarse la LOTC para que se permita el amparo directo frente a leyes como respuesta a otra figura híbrida y excepcional cual es la ley singular. 
La Constitución alemana prevé en el artículo 93.1.4.a) el amparo constitucional contra cualquier lesión de los derechos fundamentales producido por los «poderes públicos», sin limitar al legislativo como ocurre en la LOTC. En España, la restricción del amparo frente a leyes no tiene su origen en la Constitución. Al contrario, el amparo procede frente a la violación de un derecho fundamental sin que la Constitución establezca limitación alguna basada en la categoría del acto causante de la lesión. En las primeras interpretaciones doctrinales de la Constitución, antes de la aprobación de la LOTC, se había mantenido que el recurso de amparo podía ser ejercido contra leyes cuando éstas fueran autoaplicativas (S. Galeotti, B. Rossi, 1979, 1138). La exclusión del amparo frente a leyes es incorporada por el legislador al elaborar la ley de desarrollo del Tribunal Constitucional tras un debate parlamentario, pues se contenía en el proyecto de ley presentado por el Gobierno (7). Por tanto, bastaría con la reforma de esta Ley.

Deberían reformarse, en este sentido, los artículos 42 y 55.1 LOTC para hacer posible en España el amparo frente a leyes. Habría que separar en el artículo 42 el supuesto actual del amparo contra las decisiones o actos sin valor de ley emanados de las Cortes o de las Asambleas autonómicas del nuevo supuesto de amparo directo contra la ley singular (J. M. Díaz Lema, 2013, 73) e incorporar, en este sentido, también la declaración de inconstitucionalidad.

Se trataría, simplemente, de recuperar un precepto similar al incluido en el proyecto de LOTC presentado en las Cortes Generales. Aquel artículo 46.2 decía: «Cuando por ley o por disposición o acto con valor de ley formal, del Estado o de las CCAA que hubieren de ser cumplidas directamente, sin previo requerimiento o acto de sujeción individual, se violen o pongan en peligro actual o inmediato los derechos y libertades susceptibles de amparo constitucional, la persona directamente afectada [...] podrá interponer recurso de amparo ante el TC». De esta forma quedaría garantizada al menos la defensa de los derechos fundamentales susceptible de amparo constitucional frente a medidas legislativas que afecten a la situación jurídica subjetiva. Se podría plantear el recurso frente a la ley bien por la lesión material de un derecho susceptible de amparo o, en todo caso, por violación del artículo 14, ante un tratamiento singular injustificado o no razonable.

(7) Un relato del debate parlamentario sobre este proyecto de ley y, en concreto, de las enmiendas que provocaron la eliminación de amparo frente a leyes puede consultarse en mi trabajo: «Defensa judicial versus ley singular de intervención (Comentario a la sentencia del Tribunal Europeo de Derechos Humanos de 23 de junio de 1993 sobre el caso Rumasa)», cit., pág. 318. 
En cualquier caso, resulta obvio que siquiera en este supuesto se alcanzaría, en puridad, la garantía equivalente de la tutela judicial a la que se refiere el Tribunal Constitucional, pues el problema es que se eliminan las posibilidades ordinarias de control judicial propias de los actos administrativos que alcanzan a cualquier infracción del ordenamiento jurídico y se deja abierta únicamente la vía del control de constitucionalidad que se circunscribe a un único parámetro, la conformidad con la Constitución, ceñida en este caso a la lesión de los derechos fundamentales susceptibles de amparo constitucional cuando tuviera «trascendencia constitucional».

Tras una hipotética modificación legislativa que incorpore el amparo frente a leyes la tutela jurisdiccional de la ley singular existe pero no es equiparable a la que brindan los órganos jurisdiccionales ordinarios. No obstante, el propio Tribunal Constitucional parece aceptar esa posibilidad cuando indica que «no cabe afirmar en modo alguno que la satisfacción del derecho a la tutela judicial efectiva de los titulares de derechos e intereses legítimos afectados [...] requiera, necesariamente, de un pronunciamiento de los tribunales de la jurisdicción contencioso-administrativa» (STC 129/2013, FJ 5). Lo que significa, por tanto, que, en principio, puede llevarse a cabo por el Tribunal Constitucional.

A mi juicio, también aquí debería establecerse una distinción. Cuando estamos ante una ley directamente autoaplicativa, sin posibilidad alguna de actos de aplicación, la garantía de constitucionalidad que ofrece el Tribunal Constitucional es insuficiente y, por tanto, habría que afirmar de manera rotunda que estas leyes no tienen cabida en nuestro ordenamiento ni siquiera previa reforma de la legislación procesal constitucional que habilite su control directo en amparo a instancia del ciudadano. Sin embargo, cuando es una ley singular en virtud de sujeto o del objeto resultaría posible esa merma de la garantía jurisdiccional teniendo en cuenta que los actos de aplicación, en su caso, podrían ser recurridos ante la jurisdicción ordinaria. En ese caso estaríamos, utilizando los términos del Tribunal Constitucional, ante una «incidencia de forma directa, aunque no necesariamente ilegítima» en la tutela judicial efectiva.

\section{El reforzamiento de las garantías democráticas en el proceso de elaboración}

Sin embargo, como se ha apuntado antes, en estos supuestos las limitaciones a la garantía jurisdiccional, vinculadas a la forma de ley, deben complementarse con el reforzamiento del debate público y, en definitiva, el carácter democrático, que se vincula precisamente a esta fuente. Esto significa que en los casos excep- 
cionales en los que se utilice la figura de la ley singular, más allá de garantizarse el acceso directo al Tribunal Constitucional a instancia de los afectados debería exigirse el refuerzo de su carácter democrático-pluralista.

Se refería a ello el recurso de inconstitucionalidad que dio lugar a la STC 129/2013 cuando cuestiona que se haya acudido a una «vía legislativa especial, la lectura única, que reduce drásticamente las posibilidades de participación de los representantes del pueblo». Sin embargo, en este punto la sentencia no cuestiona la actuación del legislador. No introduce la variable de que estamos ante un fenómeno legislativo que requiere mayores garantías democráticas sino que utiliza una argumentación puramente formal. Entiende el Tribunal Constitucional que «el reglamento permitía acudir a este procedimiento excepcional cuando su naturaleza lo aconseje o la simplicidad de su formulación lo permita». En este sentido, rechaza la vulneración del principio democrático porque la simplicidad requerida por el reglamento parlamentario existía en este caso y porque «este concepto jurídico indeterminado es, por otra parte, totalmente ajeno, en contra de lo que afirman los recurrentes, al consenso político que pudiera suscitar el proyecto de ley o la repercusión pública que este pueda tener o a la complejidad material intrínseca que supone la función administrativa de aplicación del ordenamiento jurídico, que no se ha trasladado en modo alguno a la formulación de la ley» (FJ 10).

La cuestión no parece baladí. Sorprende que un Tribunal receloso ante una forma excepcional de legislar, con numerosos límites materiales y que pretende prácticamente impedir desde el parámetro de la tutela judicial efectiva de los afectados por esta medida, no cuestione las limitaciones al debate público y a la participación de las minorías en su tramitación parlamentaria. Esa excepcionalidad del fenómeno, e incluso el riesgo de su uso para limitar su control jurisdiccional, debería resultar suficiente para impetrar desde el principio democrático un procedimiento de elaboración que garantice el adecuado conocimiento de esta actuación legislativa excepcional y la posibilidad de participación de las minorías sin limitaciones. Por ello, el Tribunal Constitucional debería exigir al legislador singular la tramitación de su actuación con las mayores garantías de control democrático, lo que supone excluir procedimientos abreviados como el procedimiento de lectura única o la utilización de fuentes que limitan la participación de las minorías, como el Decreto-ley. Debe ser una consecuencia en la tramitación parlamentaria de la excepcionalidad que caracteriza a esta forma de legislar.

Ya sabemos que el problema en la actualidad no es la ley singular, esto es, la ausencia de generalidad y abstracción, sino su naturaleza de medida en cuanto, dicho en los términos clásicos de Forsthoff, el peligro para el Estado 
de Derecho procede de la conversión de la ley en medida. Un fenómeno legislativo propio del constitucionalismo de posguerra que pretende articular una sociedad conflictiva y compleja, para la que no resulta adecuada en cualquier circunstancia la regla universal, es utilizado de manera recurrente por el poder político para suplantar a la actividad administrativa, evitando con ello el control jurisdiccional ordinario y haciendo inmune la decisión política. Por tanto, la cuestión no es volver a reconocer la exigencia de generalidad, importante para hacer posible el garantismo social e incluso para configurar un nuevo sujeto social (C. de Cabo, 111-113), sino, más allá de su control jurisdiccional, incardinar la ley singular en una concepción democrática de la ley, esto es, imponerle también el cumplimiento de determinados requisitos vinculados al principio democrático. El fenómeno de la ley singular no sólo responde a la crisis de la generalidad sino también a la crisis democrática de la ley en la actualidad y ante ello resulta necesario configurar un concepto democrático de ley que reconozca su carácter general y abstracto salvo en supuestos excepcionales, que establezca los mecanismos para la garantía de la tutela judicial efectiva frente al legislador en los términos expuestos, pero, además, cuente con garantías democráticas en su proceso de elaboración, sin poder acogerse a los procedimientos que ineludiblemente las limitan. Sólo en esas condiciones, ciertamente excepcionales, debe resultar posible la aprobación de leyes singulares.

La ley se convierte en estos supuestos en un instrumento de acción política no sometido de forma adecuada ni al control jurisdiccional ni al control de la minoría parlamentaria, lo que obstaculiza las dos características ínsitas al principio democrático: el control del poder y la garantía de los derechos de los ciudadanos. El fenómeno de las leyes singulares refleja claramente la quiebra de los supuestos legitimadores de la ley, más allá de sus presupuestos culturales (expresión de la voluntad general frente a fragmentación jurídica y desformalización), que va, más allá de su control jurisdiccional. Nos referimos, lógicamente, a la administrativización de la ley, instrumentalizada para nuevos objetivos y circunstancias, que hemos advertido con nitidez en estas páginas pero también al deterioro crítico y funcional del Parlamento, sometido a la burocracia partidista o la pérdida de eficacia que muestra el cambio continuo ( $\mathrm{C}$. de Cabo, 77-78).

La ley es un instrumento del ejecutivo para implementar medidas normativas sectoriales que se imponen sin debate público sino mera ratificación del parlamento, para evitar el control, tanto jurisdiccional como político. En esta situación, que muestra nítidamente el fenómeno de las leyes singulares y, en concreto su utilización suplantadora de actos administrativos que permite soslayar los efectos de su control jurisdiccional, debemos plantear un concepto de ley 
que resista frente a las causas externas de sus crisis, vinculándola al principio democrático.

Ello requiere modificaciones en el funcionamiento del sistema político y la estructura del ordenamiento jurídico que apenas podemos mencionar, sino simplemente apuntar sus objetivos y líneas de actuación. Así, la realización efectiva del pluralismo; la exigencia democrática de que la ley sea conocida por la ciudadanía o el fortalecimiento del Parlamento frente al ejecutivo.

Estos condicionantes, aplicables a cualquier tipo de ley, resultan especialmente pertinentes en relación a una forma de legislar de carácter excepcional que refleja en supuestos como los aquí analizados las consecuencias perniciosas para el Estado de Derecho de la crisis de la ley.

Desde esta perspectiva resulta lógico que se exija a la ley singular de forma especialmente exigente los requisitos propios de una concepción democrática de la ley: una adecuada técnica legislativa que impida su incorporación a leyes ómnibus, etc., la transparencia en la actuación del legislador mediante el máximo conocimiento público de la tramitación legislativa, la exclusión de los procedimientos legislativos que impiden el pleno debate en sede parlamentaria, esto es, la exclusión de aprobación en Comisión, lectura única o procedimiento de urgencia, y la imposibilidad de incluirse en fuentes que limitan la participación de las minorías, como el Decreto-ley.

Aspiramos a una ley en la que, por un lado, se refuerce la garantía democrática de la decisión política y, por otro, se amplíe la base legitimadora. En el supuesto de las leyes singulares esa aspiración debería convertirse en exigencia constitucional desde el principio democrático, a partir de su carácter excepcional. Por ello, más que negar su existencia constitucional, como pretende la reciente doctrina del Tribunal Constitucional, lo que no resulta fácil de mantener en el tiempo en el contexto de una sociedad pluralista que requiere intervenciones específicas también del legislador, planteamos el refuerzo de sus garantías. A su excepcionalidad vinculada a la trascendencia del supuesto de hecho derivada del principio de igualdad y la necesidad de incluir cauces directos de control de la ley por el Tribunal a instancias del afectado, aunque no sean asimilables a los que ofrece la jurisdicción ordinaria, derivada del derecho a la tutela judicial efectiva, debería añadirse, a nuestro juicio, la exigencia de garantías de participación de las minorías y debate público en el procedimiento de elaboración de una ley singular, derivada de la aplicación del principio democrático a una actuación legislativa excepcional y limitadora de la tutela judicial efectiva.

Revista Española de Derecho Constitucional 


\section{BIBLIOGRAFÍA CITADA}

AriÑo OrTiZ, G. (1989): «Leyes singulares, leyes de caso único», Revista de Administración Pública, núm. 118, págs. 57-101.

Balaguer Callejón, F. (1992): Fuentes del Derecho. II. Ordenamiento general del Estado y ordenamientos autonómicos, Madrid, Tecnos.

BoIX PALOP, A. (2005): «Las leyes de convalidación en el ordenamiento constitucional», Revista Española de Derecho Constitucional, núm. 73, págs. 157-186.

BOUAZZA ARIÑO, O. (2008): «Desclasificación por ley singular de espacios naturales protegidos y derechos procesales (El caso de la Ciudad del Medio Ambiente)», Revista Española de Derecho Administrativo, núm. 138, págs. 259-285.

De Cabo Martín, C. (2000): Sobre el concepto de ley, Madrid, Trotta.

DíAz LEMA, J. M. (2013): «El fin del privilegio de la ley singular: comentario a la STC 129/2013», El Cronista del Estado Social y democrático de Derecho, núm. 39.

FERNÁNDEZ VALVERDE, R. (2012): «La presa de Itoiz o el comienzo de una historia interminable de validaciones legislativas (STC 73/2000, de 14 de marzo, y STEDH de 27 de abril de 2004)», en E. GARCÍA DE ENTERRÍA y E. AlONSO GARCíA (coord.), Administración y justicia: un análisis jurisprudencial. Liber amicorum Tomas-Ramón Fernández, vol. 2.

GAleotti, S., y Rossi, B. (1979): «El Tribunal Constitucional en la nueva Constitución española», Revista de Estudios Políticos, núm. 7, págs. 119-143.

Montilla Martos, J. A. (1994): Las leyes singulares en el ordenamiento constitucional español, Madrid, Civitas.

- (1994): «Defensa judicial versus ley singular de intervención (Comentario a la sentencia del Tribunal Europeo de Derecho Humanos de 23 de junio de 1993 sobre el caso Rumasa)», Revista Española de Derecho Constitucional, núm. 40, págs. 291321.

MorTATI, C. (1968): Le leggi provvedimento, Milano, Giuffrè.

ORTEGA BERNARDO, J. (2007): «Límites constitucionales en la adopción por ley de medidas concretas de carácter administrativo. Comentario a la STC 48/2005, sobre la Ley de expropiación para la ampliación de la sede del Parlamento de Canarias», Revista de Administración Pública, núm. 172, págs. 293-305.

SANTAMARÍA ARINAS, R. J. (2014): «Leyes singulares, tutela judicial efectiva y recepción de la doctrina Boxus por el Tribunal Constitucional español», Revista de Administración Pública, núm. 193, págs. 165-195.

STARCK, C. (1979): El concepto de ley, Madrid, CEC, 1979.

Revista Española de Derecho Constitucional

ISSN-L: 0211-5743, núm. 104, mayo-agosto (2015), págs. 269-295

http://dx.doi.org/10.18042/cepc/redc.104.09 
